\title{
Pollen Transmission of Asparagus virus 2 (AV-2) May Facilitate Mixed Infection by Two AV-2 Isolates in Asparagus Plants
}

\author{
Ryusuke Kawamura, Hanako Shimura, Tomofumi Mochizuki, Satoshi T. Ohki, and Chikara Masuta
}

First, second, and fifth authors: Graduate School of Agriculture, Hokkaido University, Sapporo 060-8589, Japan; and third and fourth authors: Graduate School of Life and Environmental Sciences, Osaka Prefecture University, Sakai, Osaka, Japan. Accepted for publication 5 February 2014.

\begin{abstract}
Kawamura, R., Shimura, H., Mochizuki, T., Ohki, S. T., and Masuta, C. 2014. Pollen transmission of Asparagus virus 2 (AV-2) may facilitate mixed infection by two AV-2 isolates in asparagus plants. Phytopathology 104:1001-1006.

Asparagus virus 2 (AV-2) is a member of the genus Ilarvirus and thought to induce the asparagus decline syndrome. AV-2 is known to be transmitted by seed, and the possibility of pollen transmission was proposed 25 years ago but not verified. In AV-2 sequence analyses, we have unexpectedly found mixed infection by two distinct AV-2 isolates in

normally prevented by cross protection, we suspected that pollen transmission of AV-2 is involved in mixed infection. Immunohistochemical analyses and in situ hybridization using $\mathrm{AV}$-2-infected tobacco plants revealed that AV-2 was localized in the meristem and associated with pollen grains. To experimentally produce a mixed infection via pollen transmission, two Nicotiana benthamiana plants that were infected with each of two AV-2 isolates were crossed. Derived cleaved-amplified polymorphic sequence analysis identified each AV-2 isolate in the progeny seedlings, suggesting that pollen transmission could indeed result in a mixed infection, at least in $N$. benthamiana.
\end{abstract} two asparagus plants. Because mixed infections by two related viruses are
Asparagus virus $2(\mathrm{AV}-2)$ is a member of the genus Ilarvirus and classified in subgroup 2. AV-2 alone causes no significant symptoms but plant vigor progressively declines over time through double infection with AV-2 and Asparagus virus 1 (AV-1) (18); thus, virus infection is thought to be responsible for asparagus decline disease (7). Asparagus viruses have been detected widely in most commercial asparagus plantings due to their multiple transmission strategies. AV-1 is transmitted by numerous aphid species but not through seed. On the other hand, AV-2 is primarily transmitted by seed and also mechanically by AV-2contaminated sap on cutting knives (7). In addition, AV-2 spreads among female plants downwind of $\mathrm{AV}$-2-infected asparagus, indicating the possibility of pollen transmission (7). Although $\mathrm{AV}-2$ has been found on the exine of asparagus pollen (4), providing evidence of $\mathrm{AV}-2$-contaminated pollen, pollen transmission of AV-2 from male to female plants has not yet been demonstrated experimentally.

Seed transmission of some members of the genus Ilarvirus, to which AV-2 belongs, has been extensively studied (12). For example, Prunus necrotic ringspot virus was detected in the apricot reproducing tissues, including the embryo and pollen grains $(1,2)$. Prune dwarf virus was also found in the developing flower organs and pollen grains (16). These observations suggest that the two ilarviruses can be vertically transmitted from gametes to seedlings of the next generation. Similarly, AV-2 can be vertically transmitted; however, whether the virus can enter the embryo and pollen grains has not been established.

Corresponding author: C. Masuta; E-mail address: masuta@res.agr.hokudai.ac.jp

The first and second authors equally contributed to this work.

*The $\boldsymbol{e}$-Xtra logo stands for "electronic extra" and indicates that Figure 3 appears in color online.

http://dx.doi.org/10.1094/PHYTO-12-13-0348-R

(c) 2014 The American Phytopathological Society
Because of the efficient transmission of $\mathrm{AV}-2$, infection occurs wherever asparagus is grown and transportation of AV-2-contaminated seed appears to disseminate worldwide. In fact, we have previously found that asparagus spears grown in various countries were frequently infected with AV-2. Furthermore, we found that the genetic variability of the coat protein $(\mathrm{CP})$ and $2 \mathrm{~b}$ genes of $\mathrm{AV}-2$ isolates was very low, and both genes were highly conserved, with $>99 \%$ identity among isolates (15). We analyzed $>30$ AV-2 isolates that were collected from asparagus spears bought in the market or grown in our university fields, and we have always isolated only one $\mathrm{AV}-2$ sequence from an individual plant. Recently, we isolated two distinct AV-2 sequences from some asparagus plants which were collected in our university fields. Because mixed infection with two closely related isolates of a single virus can be prevented by cross-protection, we hypothesized that AV-2 transmission through pollination might be involved in mixed infection. To verify this hypothesis, we conducted experiments to transmit $\mathrm{AV}-2$ on pollen using Nicotiana tabacum and $N$. benthamiana, two systemic hosts that are amendable to cross-protection. In this study, we analyzed whether AV-2 can be localized on the shoot apical meristem by immunohistochemical microscopy and in situ hybridization, and provide experimental evidence that AV-2 can be transmitted by pollen and that pollen transmission may play an important role in mixed infection with $\mathrm{AV}-2$ isolates in asparagus plants.

\section{MATERIALS AND METHODS}

Virus and plant materials. $\mathrm{AV}-2$ strain $\mathrm{J}$ was provided by I. Fujisawa and S. Tsuda (NARO Agricultural Research Center, Tsukuba, Japan). AV-2 strain MM8 was isolated from an asparagus plant in a field of Hokkaido University, Japan. Because AV-2 is often localized in their infected asparagus plants, and viral accumulation levels can vary greatly depending on the asparagus's growth stage, it is difficult to confirm whether an asparagus seedling is absolutely free from viruses. Therefore, we used either tobacco ( $N$. tabacum 'BY4') or N. benthamiana plants to analyze 
viral distribution in meristematic tissues and demonstrate experimentally pollen transmission of the virus.

Antibody preparation against AV-2. The $\mathrm{CP}$ gene of $\mathrm{AV}-2$ MM8 was inserted in pMAL-c2X (New England Biolabs, Beverly, MA) and expressed as a C-terminal fusion with maltosebinding protein in Escherichia coli BL21 cells. The E. coliexpressed fusion protein was then purified with an amylose resin column according to the manufacturer's instructions and used to raise antibodies against $\mathrm{AV}-2 \mathrm{CP}$.

Tissue processing for in situ hybridization. Samples from three to four individual plants were fixed in FAA (50\% ethanol, $5 \%$ formalin, and $5 \%$ acetic acid) at $4{ }^{\circ} \mathrm{C}$ overnight. After dehydration in a graded series of ethanol solutions (50, 70, 90, and $100 \%$ ) and infiltration, the samples were embedded in paraffin (Paraplast-plus; Sigma-Aldrich, St. Louis). Sections (10 $\mu \mathrm{m})$ were cut with a rotary microtome (RM2125RT; Leica, Wetzlar, Germany), placed on a warming plate at $37^{\circ} \mathrm{C}$ overnight, then dewaxed in xylene and washed in $100 \%$ ethanol. After hydration through a graded ethanol series $(90,70,50$, and $30 \%)$ followed by distilled water, the sections were used for immunohistochemistry or in situ hybridization.

Immunohistochemistry analyses. The AV-2 $\mathrm{CP}$ protein was detected in the meristem using immunohistochemistry, essentially as described for Cucumber mosaic virus (CMV) detection (11, 17). Briefly, sections were soaked in a blocking solution (phosphate-buffered saline [PBS], $\mathrm{pH} 7.0$, containing 4\% skim milk and $0.05 \%$ Tween 20 [PBSTM]) for $1 \mathrm{~h}$. Sections were then incubated with an antibody to the AV-2 $\mathrm{CP}$ diluted 1:500 in PBSTM for $2 \mathrm{~h}$ at room temperature, washed three times in PBS containing $0.05 \%$ Tween 20 (PBST) for $5 \mathrm{~min}$, then incubated with an alkaline phosphatase (AP)-conjugated anti-rabbit immunoglobulin G (Zymed Laboratories, San Francisco) diluted 1:1,000 in PBSTM at $4^{\circ} \mathrm{C}$ overnight, and washed three times for $5 \mathrm{~min}$ in PBST. The sections were stained using a Vector Blue Alkaline Phosphatase Substrate Kit (Vector Laboratories, Burlingame, CA). In all, >50 stained sections were examined with a BX-51 light microscope (Olympus, Tokyo).

In situ hybridization. In situ hybridization was performed to detect AV-2 RNA in the meristem, essentially as previously described $(11,17,22)$. Briefly, sections were washed with $2 \times$ SSC ( $1 \times \mathrm{SSC}$ is $0.15 \mathrm{M} \mathrm{NaCl}$ plus $0.015 \mathrm{M}$ sodium citrate) for $5 \mathrm{~min}$, then covered with a prehybridization solution (50\% formamide, $300 \mathrm{mM} \mathrm{NaCl}, 10 \mathrm{mM}$ Tris- $\mathrm{HCl}$ [pH 8.0], $1 \mathrm{mM}$ EDTA, 1× Denhardt's solution, $0.25 \%$ sodium lauryl sulfate, and $1 \%$ dextran sulfate) and incubated for $1 \mathrm{~h}$ at $42^{\circ} \mathrm{C}$. After the prehybridization solution had been removed, the sections were incubated in a hybridization solution containing a digoxigenin (DIG)-labeled (Roche Diagnostics, Basel, Switzerland) RNA probe complementary to the entire AV-2 $\mathrm{CP}$ sequence for $12 \mathrm{~h}$ at $42^{\circ} \mathrm{C}$. The sections were washed $15 \mathrm{~min}$ at room temperature twice with $2 \times$ $\mathrm{SSC}$ and at $50^{\circ} \mathrm{C}$ twice each with $0.2 \times \mathrm{SSC}$ and $0.1 \times \mathrm{SSC}$. The sections were washed in buffer I $(0.1 \mathrm{M}$ maleic acid and $0.15 \mathrm{M}$ $\mathrm{NaCl}, \mathrm{pH}$ 7.5) for $5 \mathrm{~min}$, and incubated in a blocking solution (1\% Blocking Reagent [Roche Diagnostics] in buffer I) for $30 \mathrm{~min}$, followed by incubation in a 1:1000 dilution of alkaline phosphatase-conjugated anti-DIG antibody (Roche Diagnostics) for $1 \mathrm{~h}$. The sections were washed twice in buffer 1 for $15 \mathrm{~min}$. After a final wash with AP buffer $(100 \mathrm{mM}$ Tris- $\mathrm{HCl}, 100 \mathrm{mM}$ $\mathrm{NaCl}$, and $5 \mathrm{mM} \mathrm{MgCl}, \mathrm{pH} 9.5$ ), the sections were incubated with the color substrate solution (NBT/BCIP in AP buffer) in the dark. In total, $>50$ stained sections were examined with a BX-51 light microscope.

Quantitative reverse-transcription polymerase chain reaction. Total RNA was isolated using Trizol reagent (Invitrogen, Carlsbad, CA) according to the manufacturer's instructions. For the quantitative reverse-transcription polymerase chain reaction (RT-PCR), $1 \mu \mathrm{g}$ of total RNA was used as a template for cDNA synthesis. First-strand cDNA was synthesized using a Takara
RNA PCR kit (Takara, Ohtsu, Japan) with a random primer. Quantitative RT-PCR was carried out using $1 \mu$ of the RT reaction mixture and SYBR green mixture (Takara) in the DNA Engine Opticon 2 System (MJ Research, Waltham, MA). For the amplification of the AV-2 CP gene, primer pair AV2-217F (5'TGGCACGAGGTTTCTGGGTATT-3') and AV2-430R (5'-CCG GAGCGATAGGATGAATTTG-3') was used. The $N$. benthamiana actin gene was amplified as an internal control using primer pair Nb-act5-120 (5'-GCGGGAAATTGTTAGGGATGT$\left.3^{\prime}\right)$ and $\mathrm{Nb}$-act3-120 (5'-CCATCAGGCAGCTCGTAGCT-3').

Derived cleaved-amplified polymorphic sequence analysis of the relative accumulation of the two $\mathrm{AV}-2$ isolates. The proportion of each isolate (MM8 or J) in the viral population was estimated by derived cleaved-amplified polymorphic sequence (dCAPS) analysis, which is often used to detect single-nucleotide polymorphisms. Total RNAs were extracted from pools of three tissues in infected leaves with Trizol reagent. The entire AV-2 CP gene was then amplified by RT-PCR using a Takara One-Step RNA PCR kit (Takara) and primer pair AV2-CP5-650 (5'ATGTCTGGTAATGCTATTGAAGTTAATGG-3') and AV2-CP3650 (5'-TCATTCCTCAACAACCAAGAAA- $\left.3^{\prime}\right)$. We introduced a restriction site (SpeI) at position 484 (from the $5^{\prime}$ end of the $\mathrm{CP}$ gene) in the PCR product amplified by a primer pair, which brings a point mutation to artificially create an SpeI site. By cutting the PCR product with SpeI, we can identify the AV-2 isolate by the sizes of the PCR products. Thus, we performed nested PCR using a sample of the product from the primary RTPCR using primer pair AV2-5-Spe (5'-CAAATTCATCCT ATCGCTCC-3') and AV2-3-Spe (5'-CTTAACTTCGGAAACCG TAGTACTAG- $3^{\prime}$ ), and cut the PCR product with SpeI, which cleaves the PCR product obtained from MM8 but not from J.

Pollination between AV-2-infected $N$. benthamiana plants. Pollen from the anther of a flower on the AV-2-J-infected $N$. benthamiana plant was transferred to the stigma of a flower on the AV-2-MM8-infected $N$. benthamiana plant from which the anthers had been removed before the stigma matured, and vice versa.

Cross-protection assay. Sap from tobacco leaves infected with either isolate $\mathrm{AV}-2-\mathrm{J}$ or $\mathrm{AV}-2-\mathrm{MM} 8$ was used as inoculum (as either the protective virus or the challenge virus) for four plants in each of two independent experiments. Seven days after plants were inoculated with the protective virus, the same inoculated leaves were inoculated with the challenge virus. Ten days after inoculation with the challenge virus, the proportion of each virus in the upper noninoculated leaves was analyzed by dCAPS.

\section{RESULTS}

Identification of a mixed infection of two AV-2 isolates in asparagus plants. Our previous sequence analyses (15) showed that only a few nucleotides at various positions in the $\mathrm{CP}$ sequence differed among distinct $\mathrm{AV}-2$ isolates from commercial asparagus plants collected from different asparagus-producing areas in the world and, in most cases, only a single AV-2 sequence was identified from one plant. In this study, we found that two $\mathrm{AV}-2$ sequences were present in a female asparagus plant grown in our university field; nine cDNA clones of the CP gene were distinguished by the ratio of four to five. We identified one nucleotide difference as a nonsynonymous variation that distinguishes the two AV-2 sequence variants. Because viruses normally exist in a population of closely-related genomic sequences (quasispecies), sequence variations in the viral cDNA clones are often found by cDNA sequencing. However, when we determined the $\mathrm{CP}$ sequences from $>30 \mathrm{AV}-2$ isolates, we always obtained a single sequence for each isolate, suggesting that the sequence variations of a quasispecies are not apparent in AV-2 but a major sequence of $\mathrm{AV}-2 \mathrm{CP}$ is predominant in commercial asparagus plants. Considering the very low sequence variability in the AV-2 
$\mathrm{CP}$ sequences, the existence of this unique nucleotide variation suggests the possibility of a mixed infection of two distinct AV-2 isolates in the female plant. Encouraged by this finding, we further investigated whether other asparagus plants in our field are mixed infected by two AV-2 variants. After sequencing the cDNA clones of the CP gene, we found one more mixed infection with two AV-2 sequences in one of the analyzed supermale plants. Twelve cDNA clones of the CP gene were distinguished by the ratio of six to six, and two nucleotide differences were identified as nonsynonymous variations.

Localization of $\mathrm{AV}-2$ in the apical meristem and the anther of a systemically infected tobacco plant. Approximately $20 \%$ of plant viruses are transmitted through seed (10) but the presence of a virus in a seed (for example, on seed coats) does not necessarily lead to seed transmission. True seed-transmitted viruses should be found in the embryo, and virus transmission into the embryo is achieved either by direct invasion of the embryo via the ovule or by indirect invasion of the embryo mediated by virus-infected or virus-contaminated pollen grains (9). In general, the meristematic tissue that differentiates reproductive organs is viewed as a particular type of tissue responsible for failure of virus invasion (13), and many viruses cannot enter or survive in the meristem tissue. Thus, we first analyzed whether AV-2 can invade meristem tissue in AV-2-infected tobacco plants. In our immunohistochemical analysis, AV-2 was localized not only in the corpus and leaf primordia but also in the tunica of the apical meristem, suggesting that $\mathrm{AV}-2$ can, indeed, invade meristematic tissues (Fig. 1).

Because we found that AV-2 could enter meristematic tissues, AV-2 seems to have the ability to reach the ovule and pollen. To determine the route of the mixed infection of the two AV-2 isolates, we then analyzed pollen transmission of AV-2 using immunohistochemical microscopy of the anthers of AV-2-infected tobacco flower buds at two developmental stages: a late stage in which mature pollen grains have been formed (Fig. 2) and an early stage in which anthers contained pollen mother cells (Fig. 3 ). When mature pollen grains from the late stage of the AV-2-

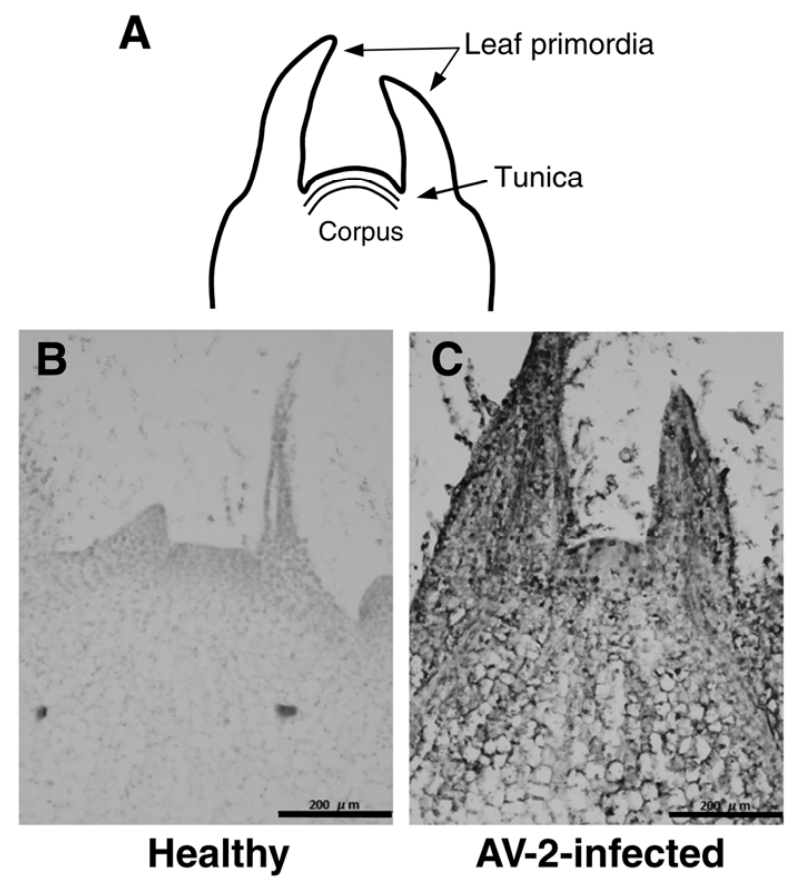

Fig. 1. Distribution of Asparagus virus $2(\mathrm{AV}-2)$ in the shoot meristem of tobacco as observed by immunohistochemical localization of AV-2 coat protein. A, Schematic diagram of meristem. B, Healthy meristem as a negative control. C, Infected meristem 36 days after inoculation with AV-2 isolate $\mathbf{J}$ (AV2-J). Infected cells are stained blue. Bars $=200 \mu \mathrm{m}$. infected anthers were analyzed, AV-2 signals were found throughout the anther tissue, and almost half of the pollen grains were stained (Fig. 2A). In the control healthy tissue, no signal was detected (Fig. 2B). On the other hand, the pollen mother cells did not seem to be stained at the early stage of anther development (Fig. 3), suggesting that AV-2 may not invade the pollen grain but that the virus was associated with the surface of the pollens. We further analyzed AV-2 infection in the anther tissue by in situ hybridization. Our in situ hybridization experiment also indicated that viral RNAs were distributed in the anther but not in the pollen mother cells (Fig. 4A); again, no viral signal was detected in the healthy anther (Fig. 4B). These results confirmed the previous observation that $\mathrm{AV}-2$ has been detected in the wash solution of the pollen grains collected from the AV-2-infected asparagus plants and also found to be localized in the exine of asparagus pollen (4).

Verification of a mixed infection with two AV-2 isolates through experimental pollen transmission between a male and a female plant infected with either virus. Observation of the presence of two distinct AV-2 isolates in asparagus plants gave us the idea that mixed infection of the two AV-2 isolates was achieved through pollination by AV-2 infected pollen grains. To test our hypothesis, we experimentally verified that a mixed
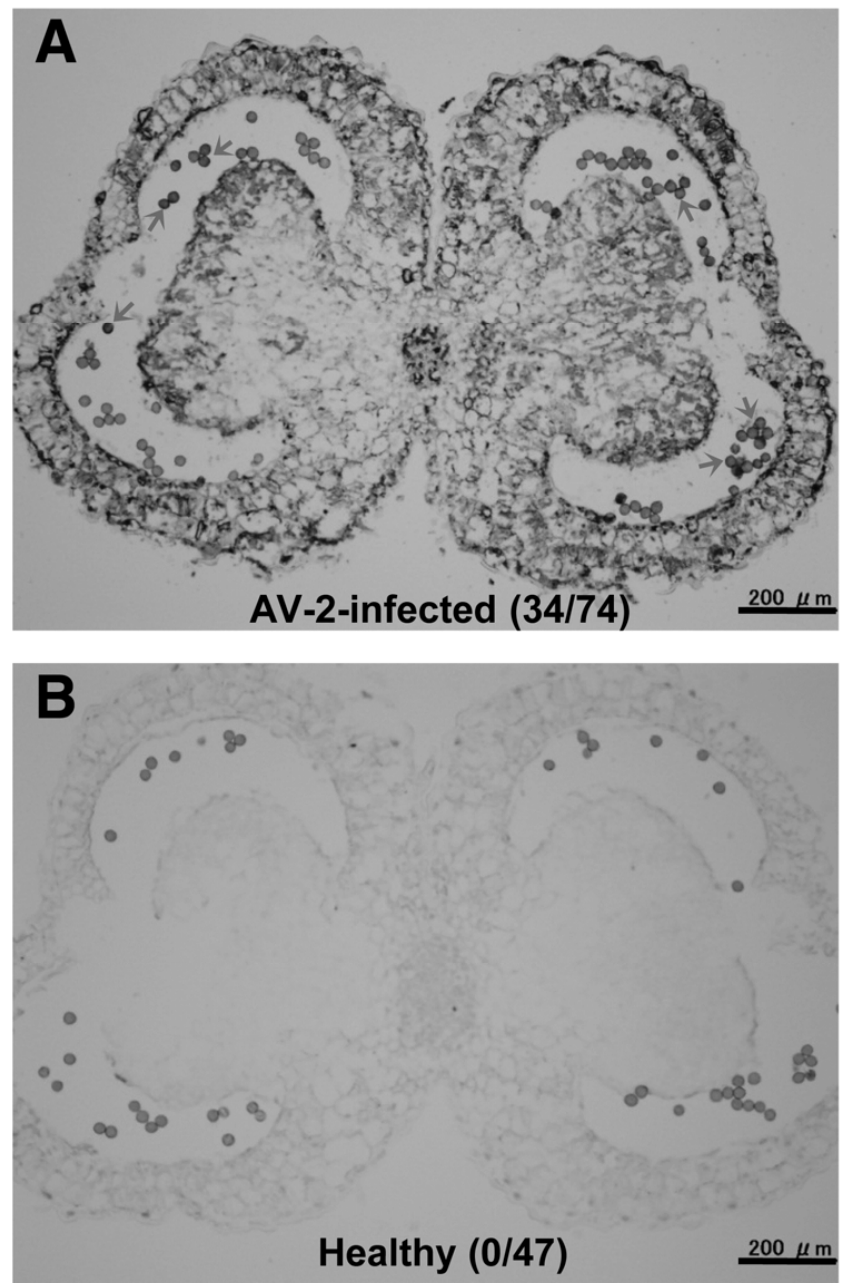

Fig. 2. Asparagus virus $2(\mathrm{AV}-2)$ coat protein immunohistochemical localization in cross section of mature anthers of tobacco. A, Infected anther. B, Healthy anther as a negative control. We examined $>50$ sections taken from three to four plants. Experiments were repeated at least twice, and similar images were obtained each time. Infected cells are stained blue (here black). Arrowheads indicate stained pollens. The number of stained pollens versus the number of total pollens observed is shown at the bottom of the image. Bars = $200 \mu \mathrm{m}$. 
infection could be generated as a result of a cross between AV-2infected parental plants. To this aim, we used two AV-2 isolates (MM8 and J) and prepared $N$. benthamiana plants infected with each isolate. Using asparagus plants for inoculation experiments is challenging because virus-free status is difficult to ascertain. In addition, in contrast to the symptomless AV-2-infected asparagus, AV-2 causes mild mottling symptoms on $N$. benthamiana. Thus, $N$. benthamiana is convenient for monitoring AV-2 infection. $\mathrm{AV}-2-\mathrm{J}$, which was isolated $>30$ years ago in the northern island
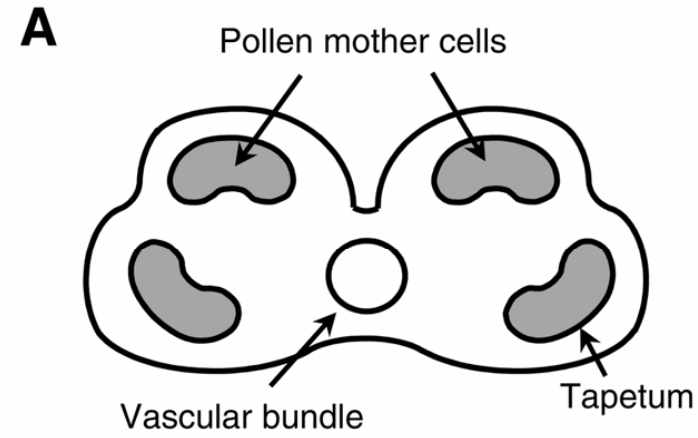

B

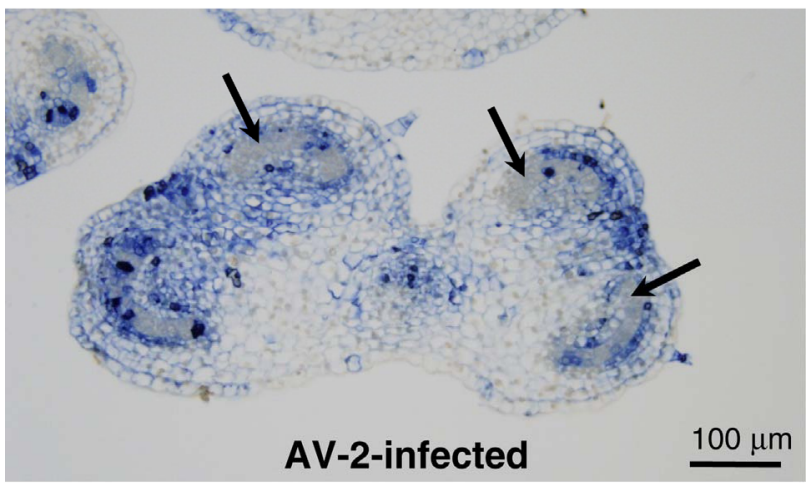

Fig. 3. Asparagus virus $2(\mathrm{AV}-2)$ coat protein immunohistochemical localization in cross section of developing, immature anthers of tobacco. $\mathbf{A}$, Schematic diagram of immature anther. B, Infected immature anther. We examined $>50$ sections taken from three to four plants. Experiments were repeated at least twice; similar images were obtained each time. Note that there is little blue color in the pollen mother cells, while infected cells are stained blue (here black). Arrowheads indicate spaces for pollen mother cells. Bar $=100 \mu \mathrm{m}$. of Japan (Hokkaido) (6), was quite different from other AV-2 isolates, with 10 nucleotides differing in the CP gene of isolates $\mathrm{J}$ and MM8. We could distinguish the two isolates using dCAPS analysis without sequencing the corresponding CP gene cDNA clones. Pollen grains from the MM8-infected plant were transferred onto a stigma of the J-infected plant, and vice versa, to obtain seed (Fig. 5A). After total RNA was extracted from the seedlings generated from the harvested seed, we conducted dCAPS analyses to identify the AV-2 isolates and verify whether pollen transmission had, indeed, occurred. As shown in representative agarose gel (Fig. 5B), we identified the AV-2 isolates in the seedlings as a result of seed transmission. Of 14 plants analyzed, we found two mixed infections $(\mathrm{MM} 8+\mathrm{J})$, one in a cross of MM8 (seed parent) $\times \mathrm{J}$ (pollen parent) and the other in a cross of $\mathrm{J} \times$ MM8 (Table 1). Interestingly, two progeny plants from MM $8 \times \mathrm{J}$ were not infected by either isolate (Table 1 ). When we compared the viral accumulation levels by quantitative RTPCR, the level of $\mathrm{J}$ was higher than that of MM8 (Fig. 5C), suggesting that $\mathrm{J}$ may be able to multiply more efficiently than MM8 in $N$. benthamiana. However, the AV-2 accumulation level seems not to affect pollen transmission because MM8 could replace $\mathrm{J}$ in the progeny plants (three of eight plants) when pollen of an MM8-infected plant was transferred onto a stigma of a J-infected plant (Table 1).

Influence of cross-protection between two AV-2 isolates on the establishment of a mixed infection. When AV-2-MM8 and $\mathrm{AV}-2-\mathrm{J}$ were co-inoculated and the viral accumulation in upper uninoculated leaves was analyzed at 14 days after inoculation, individual isolates were detected in newly developing tissues. Especially when new leaves from lateral buds were harvested, a dominant isolate was detected (Fig. 6A). However, when major leaf veins were included in the tissues from which RNA was extracted, both isolates were detected (Fig. 6A). These observations indicated that the simultaneous presence of both isolates was found to a limited extent in co-inoculated plants. Because it is rare that spontaneous co-infection with two AV-2 strains occurs in the fields, to further examine the role of cross-protection between the two isolates, $N$. benthamiana plants were first inoculated with either J or MM8 and, 7 days later, the same inoculated leaves were inoculated with the other challenging AV-2 isolate (Fig. 6B). Ten days after the second inoculation, total RNA was extracted from the upper uninoculated leaves and the infected AV2 isolate was identified by dCAPS analysis (Fig. 6C). Crossprotection between MM8 and $\mathrm{J}$ was complete regardless of the combination of the first and second AV-2 isolates (Table 2), suggesting that pollen transmission occurs over the crossprotection barrier between two AV-2 isolates.
A

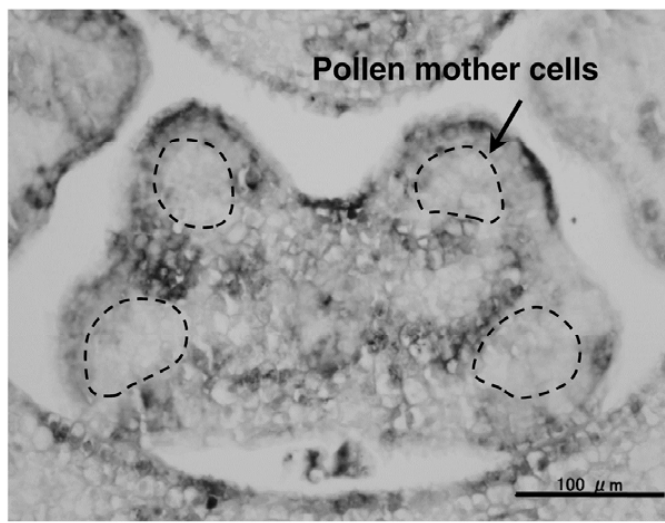

B

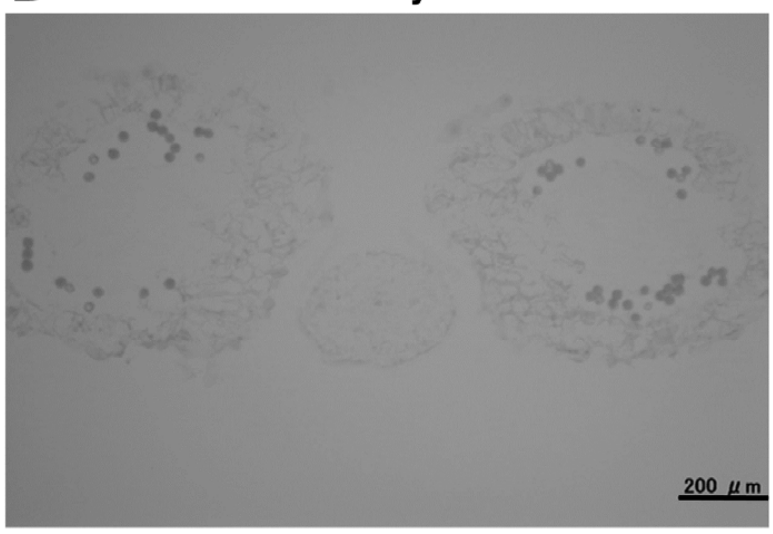

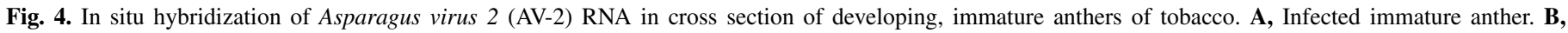

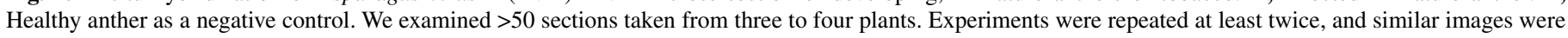
obtained each time. Infected cells are stained purple. Note a lack of purple signal in pollen mother cells. Bars $=100 \mu \mathrm{m}(\mathrm{A})$ and $200 \mu \mathrm{m}(\mathrm{B})$. 


\section{DISCUSSION}

Normally, mixed infection of two viral isolates is quite rare due to cross-protection, which has been observed when an infection by a mild strain of a virus prevents a subsequent infection by a severe strain of the same virus (19). Cross-protection is not

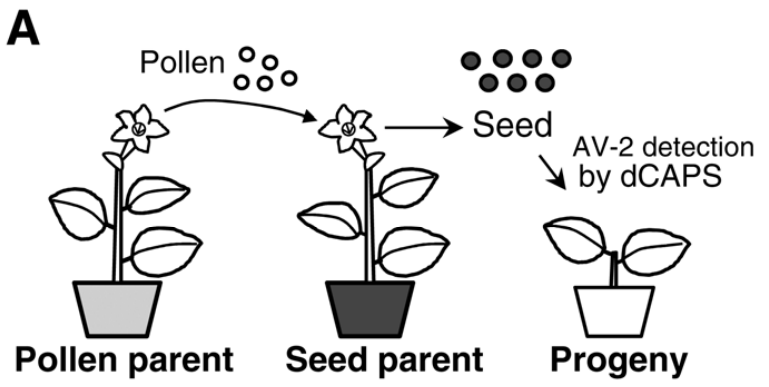

$$
\begin{aligned}
\text { MM8-infected } & \longrightarrow \text { J-infected } \\
\text { J-infected } & \longrightarrow \text { MM8-infected }
\end{aligned}
$$

Pollen transfer

B
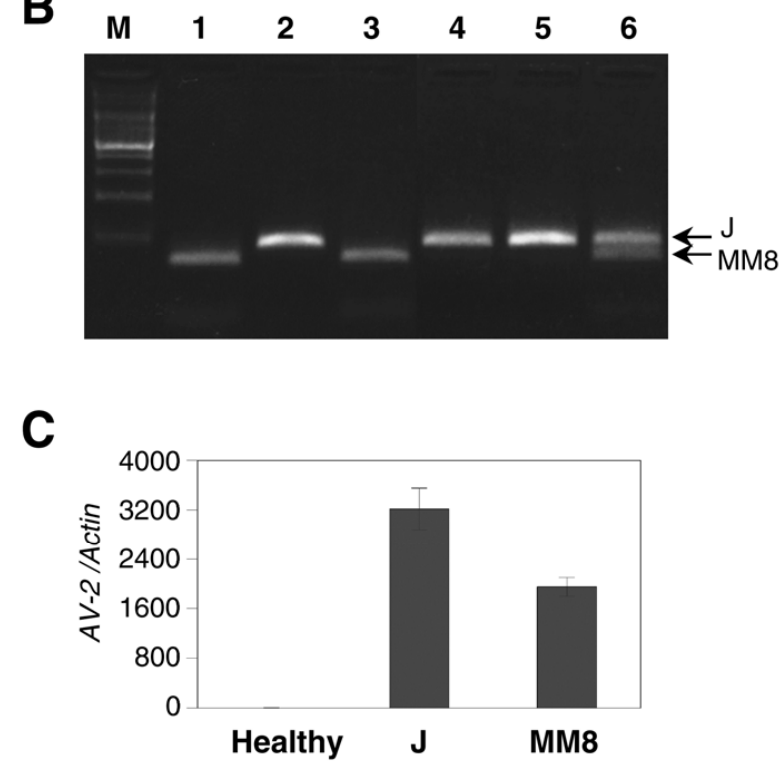

Fig. 5. Pollen transmission of Asparagus virus 2 (AV-2) between AV-2 isolate J (J)-infected and AV-2 isolate MM8 (MM8)-infected Nicotiana benthamiana plants. A, Schematic diagram of the pollen transfer experiment. B, Identification of each AV-2 isolate in the progeny plants by derived cleaved-amplified polymorphic sequence (dCAPS). The polymerase chain reaction (PCR) product (101 bases) from MM8 was designed to be cut with SpeI and generate a 79-base DNA fragment and a 22-base DNA fragment; however, the 101-base PCR product from J was not cut with SpeI. Lanes are individual plants. $\mathrm{M}=$ 100-bp DNA ladder. C, AV-2 accumulation in AV-2-infected N. benthamiana plants. Viral accumulation levels were measured by real-time reverse-transcription PCR at 21 days postinoculation. Viral levels were measured relative to the actin mRNA level. Values are means with standard deviations from three independent replicates. Note that AV-2-J accumulated to a higher level than AV-2-MM8.

TABLE 1. Identification of seed-transmitted Asparagus virus 2 (AV-2) isolates in progeny plants

\begin{tabular}{lcccc}
\hline & \multicolumn{4}{c}{ Infected/analyzed $^{\mathrm{a}}$} \\
\cline { 2 - 5 } Seed parent $\times$ pollen parent & MM8 & $\mathrm{J}$ & MM8+J & AV-2-free \\
\hline MM8-infected $\times$ J-infected & $2 / 6$ & $3 / 6$ & $1 / 6$ & $0 / 6$ \\
J-infected $\times$ MM8-infected & $3 / 8$ & $2 / 8$ & $1 / 8$ & $2 / 8$ \\
\hline
\end{tabular}

a Number of AV2-infected plants/number of analyzed plants. J and MM8 were characterized by derived cleaved-amplified polymorphic sequence. necessarily fully functional with mixed infection of two distinct isolates. Sometimes it can occur at an initial infection stage but does not last because the more competitive isolate eventually eliminates the mild isolate. For example, mixed infections of two CMV strains have been rarely observed in the field in spite of its broad host range ( $>1,200$ plant species) and worldwide distribution $(3,5,8)$. However, there is at least one good example of a possible mixed infection of two CMV variants, which were

A
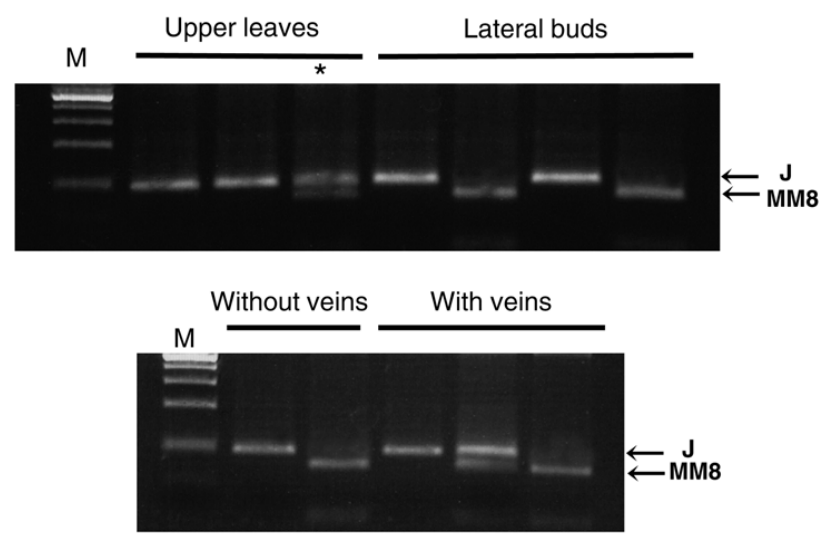

B
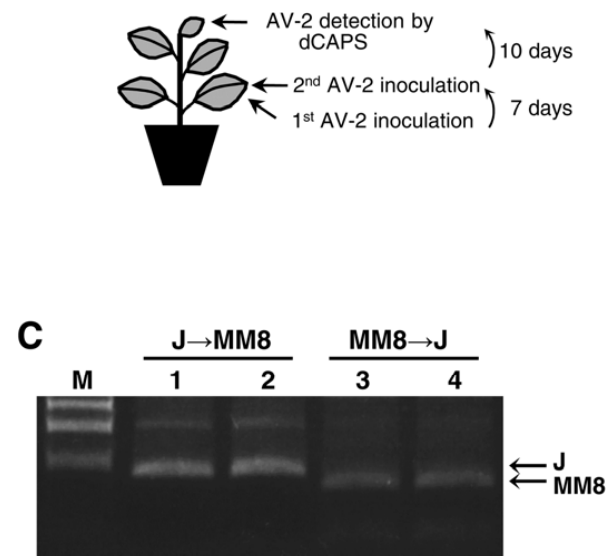

Fig. 6. Cross-protection between Asparagus virus 2 (AV-2) isolates $\mathrm{J}$ and MM8. A, Identification of each AV-2 isolate in the upper leaves of the plants co-inoculated with isolates MM8 and $\mathrm{J}$ by derived cleaved-amplified polymorphic sequence (dCAPS). Leaf samples were harvested 14 days after coinoculation. Polymerase chain reaction (PCR) products for MM8 but not for J were cleaved with SpeI. Lanes represent individual leaves. Because, in the initial experiment (upper panel), mixed infection was detected from one leaf tissue that contained major leaf veins $(*)$, the leaf tissues with or without major veins were further analyzed (lower panel). B, Schematic diagram of cross-protection assay. C, Identification of each AV-2 isolate in the upper leaves by dCAPS. $\mathrm{J} \rightarrow$ MM8 and MM8 $\rightarrow \mathrm{J}$ indicate the first (protecting) to the second (challenging) virus. PCR products for MM8 but not for J were cleaved with SpeI. For the size of the PCR products, see the legend of Figure 5. Lanes represent individual plants. $\mathrm{M}=100$-bp DNA ladder.

TABLE 2. Cross-protection between Asparagus virus 2 (AV-2) strain $\mathbf{J}$ and strain MM8

\begin{tabular}{lccc}
\hline & & \multicolumn{2}{c}{ Infected/analyzed $^{\mathrm{a}}$} \\
\cline { 3 - 4 } Protecting (1st AV-2) & Challenging (2nd AV-2) & $\mathrm{J}$ & MM8 \\
\hline J & MM8 & $4 / 4$ & $0 / 4$ \\
MM8 & J & $0 / 4$ & $4 / 4$ \\
\hline
\end{tabular}

${ }^{a}$ Number of AV2-infected plants/number of analyzed plants. J and MM8 were judged by derived cleaved-amplified polymorphic sequence. 
transmitted to the progeny seed. This mixed infection must have occurred only under the special conditions of seed transmission by pollen infection on a dioecious plant (20). One spinach breeding line was found to be infected by two distinct, seed-transmitted CMV variants (SP103 and SP104). As a result of cDNA sequencing and restriction analyses, the authors found that SP103 and SP104 coexisted in most of the tested plants at the ratio of two to one. We considered that our observation on AV-2 in asparagus, which is also a dioecious plant, is quite similar and that mixed infection of two AV-2 isolates in asparagus plants might be attributed to pollen transmission.

Our immunohistochemical microscopy and in situ hybridization suggested that $\mathrm{AV}-2$ was associated with the surface of the pollen, confirming previous observations (4), and did not directly invade the pollen grain. Although the virus cannot invade pollen grains, it is possible for the virus to reach egg cells. Virus particles on the pollen surface likely can accompany a pollen tube to the ovule. The AV-2-associated pollen tube then grows through the stigma into the style of the ovule and enters the ovule through the micropylar opening. The virus may be released into the ovule from the pollen tube or enter the egg cells with the tube nucleus, so that it may be transmitted by the seed. Therefore, we reasoned that pollen transfer is the most plausible explanation for the observed mixed infection by AV-2. According to this mechanism of transfer via a pollen tube, we consider that a subsequent isolate of AV-2 would directly translocate into the ovule (even egg cells) even after the ovule has already been infected with another AV2 strain.

RNA silencing as a mechanism for antiviral resistance is thought to play an important role in the exclusion of viruses from meristematic tissues (14). Thus, we considered that AV-2 must have the ability to invade meristematic tissues, perhaps by suppressing RNA silencing. In fact, $\mathrm{AV}-2$ has a unique type of RNA silencing suppressor (RSS) (i.e., the $2 b$ protein, which was found to function as a weak RSS against systemic silencing but not against local silencing) (15). It is conceivable that such an RSS against systemic silencing may be important for AV-2 to enter meristematic tissue, preventing the systemic small interfering RNA signals from diffusing into the meristem. Considering the similarity of pollen transmission of AV-2 virus in a dioecious plant to the seed-transmission of CMV strains in spinach, it will be interesting to know whether SP103 and SP104 can also enter shoot apical meristem tissues and how their $2 \mathrm{~b}$ proteins behave as RSSs in meristem. It is noteworthy that the $2 \mathrm{~b}$ proteins of CMV SP103 and SP104 probably have weak RSS activities because the spinach isolates belong to subgroup II CMV, whose $2 \mathrm{~b}$ proteins were found to have much weaker RSS activity than those of subgroup I CMV (21). To characterize the role of the AV-2 RSS in seed and pollen transmission, further studies are needed.

\section{ACKNOWLEDGMENTS}

This work was supported, in part, by a Grant-in-Aid for Research and Development Projects for Application in Promoting New Policy of Agriculture Forestry and Fisheries from the Ministry of Agriculture, Forestry and Fisheries (MAFF) (Japan). We thank C. Hirata for her excellent technical help.

\section{LITERATURE CITED}

1. Amari, K., Burgos, L., Pallás, V., and Sánchez-Pina, M.A. 2007. Prunus necrotic ringspot virus early invasion and its effects on apricot pollen grain performance. Phytopathology 97:892-899.

2. Amari, K., Burgos, L., Pallás, V., and Sánchez-Pina, M. A. 2009. Vertical transmission of Prunus necrotic ringspot virus: hitch-hiking from gametes to seedling. J. Gen. Virol. 90:1167-1174.

3. Bonnet, J., Fraile, A., Sacristán, S., Malpica, J. M., and García-Arenal, F. 2005. Role of recombination in the evolution of natural populations of $\mathrm{Cu}$ cumber mosaic virus, a tripartite RNA plant virus. Virology 332:359-368.

4. Evans, T. A., and Stephens, C. T. 1988. Association of asparagus virus II with pollen from infected asparagus (Asparagus officinalis). Plant Dis. 72:195-198.

5. Fraile, A., Alonso-Prados, J. L., Aranda, M. A., Bernal, J. J., Malpica, J. M., and García-Arenal, F. 1997. Genetic exchange by recombination or reassortment is infrequent in natural populations of a tripartite RNA plant virus. J. Virol. 71:934-940.

6. Fujisawa, I., Goto, T., and Tsuchizaki, T. 1983. Some properties of asparagus virus II isolated form Asparagus officinalis in Japan. Ann. Phytopathol. Soc. Jpn. 49:683-688.

7. Jaspers, M. V., and Falloon, P. G. 1999. Asparagus virus 2: A contributing factor in asparagus decline. Acta Hortic. 479:263-270.

8. Maoka, T., Saito-Hayano, Y., Iwasaki, M., Yoshida, K., and Masuta, C. 2010. Mixed infection in tomato to ensure frequent generation of a natural reassortant between two subgroups of Cucumber mosaic virus. Virus Genes 40:148-150.

9. Maule, A. J., and Wang, D. 1996. Seed transmission of plant viruses: a lesson in biological complexity. Trends Microbiol. 4:153-158.

10. Mink, G. I. 1993. Pollen- and seed-transmitted viruses and viroids. Annu. Rev. Phytopathol. 31:375-402.

11. Mochizuki, T., and Ohki, S. T. 2004. Shoot meristem tissue of tobacco inoculated with Cucumber mosaic virus is infected with the virus and subsequently recovers from infection by RNA silencing. J. Gen. Plant Pathol. 70:363-366.

12. Pallás, V., Aparício, F., Herranz M. C., Amari, K., Sánchez-Pina, M. A., Myrta, A., and Sanchez-Navarro, J. A. 2012. Ilarviruses of Prunus spp.: a continued concern for fruit trees. Phytopathology 102:1108-1120.

13. Sastry, K. S. 2013. Seed-borne Plant Virus Diseases. Springer Publishers, New Delhi, India.

14. Schwach, F., Vaistij, F. E., Jones, L., and Baulcombe, D. C. 2005. An RNA-dependent RNA polymerase prevents meristem invasion by Potato virus $X$ and is required for the activity but not the production of a systemic silencing signal. Plant Physiol. 138:1842-1852.

15. Shimura, H., Masuta, C., Yoshida, N., Sueda, K., and Suzuki, M. 2013. The $2 \mathrm{~b}$ protein of Asparagus virus 2 functions as an RNA silencing suppressor against systemic silencing to prove functional synteny with related cucumoviruses. Virology 442:180-188.

16. Silva, C., Tereso, S., Nolasco, G., and Oliveira M.M. 2003. Cellular location of Prune dwarf virus in almond sections by in situ reverse transcription-polymerase chain reaction. Phytopathology 93:278-285.

17. Sunpapao, A., Nakai, T., Dong, F., Mochizuki, T., and Ohki, S. T. 2009. The $2 \mathrm{~b}$ protein of Cucumber mosaic virus is essential for viral infection of the shoot apical meristem and for efficient invasion of leaf primordia in infected tobacco plants. J. Gen. Virol. 90:3015-3021.

18. Tomassoli, L., Zaccaria, A., and Tiberini, A. 2007. Use of one step RTPCR for detection of Asparagus virus 1. J. Plant Pathol. 89:413-415.

19. Valle, R. P., Skrzeczkowski, J., Morch, M. D., Joshi, R. L., Gargouri, R., Drugeon, G., Boyer, J. C., Chapeville, F., and Haenni, A. L. 1988. Plant viruses and new perspectives in cross-protection. Biochimie 70:695-703.

20. Yang, Y., Kim, K. S., Anderson, E. J. 1997. Seed transmission of cucumber mosaic virus in spinach. Phytopathology 87:924-931.

21. Ye, J., Qu, J., Zhang, J. F., Geng, Y. F., and Fang, R. X. 2009. A critical domain of the Cucumber mosaic virus $2 \mathrm{~b}$ protein for RNA silencing suppressor activity. FEBS Lett. 583:101-106.

22. Zhu, Y., Green, L., Woo, Y. M., Owens, R., and Ding, B. 2001. Cellular basis of potato spindle tuber viroid systemic movement. Virology 279:69-77. 